\title{
La calle, espacio público moderador de la vida en las ciudades mexicanas
}

\author{
Jesús Arturo Villa Fernández" \\ El propósito es interpretar a las ciudades como polos de inversión vista desde el turismo \\ y sus recursos naturales para desencadenar un tipo de ciudad modelo. La mayoría \\ de los planificadores se someten a variables de posición geográfica, topografía y clima \\ que determinarán el diseño urbano para organizar una ciudad y sus habitantes. No obstante, \\ es nulo el diseño urbano a partir de la autenticidad de sus actores y las calles como respuesta. \\ Son atmósferas para conocer las entrañas del sistema urbano, que tiene vida desde \\ su espacio público, ajustándose a interpretar vidas de los actores que prevalecen \\ desde generaciones atrás y al mismo tiempo de voces que se manifiestan.
}

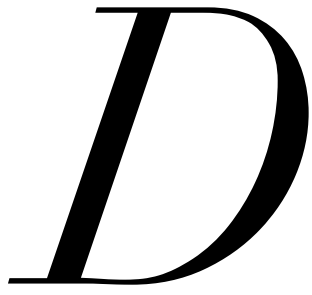

URANTE LOS AÑOS SESENTA, en muchos países del continente americano el crecimiento demográfico fue más rápido que la construcción de las ciudades. El precio del metro cuadrado por construcción ascendió contrarrestando la inversión en siembra de tierras de cultivo. Los campos de cultivo desaparecieron para ser ocupados por construcciones verticales y horizontales; entre cada construcción existen líneas intersticiales o espacios

* Docente y jefe del Departamento de Arquitectura del Instituto Tecnológico de Zacatecas y proyectista de la Unidad de Construcción de la Universidad Autónoma de Zacatecas, México. exteriores arquitectónicos urbanos para la gestión conceptual del espacio público donde aparecieron trazos homogéneos y heterogéneos para el paso del habitante en su actividad urbana; en cada semilla de construcción prolifera la existencia de un camino para desplazarse y organizar la planeación urbana.

Las ciudades desbordan movimientos telúricosurbanos $^{\mathrm{I}}$ como si fuesen sismos, producto del desplazamiento-movimiento social urbano. El alto potencial demográfico es una razón por la cual las ciudades se ven afectadas por su traza histórica, forma urbana, organización étnica-social-económica y política-religiosa que delinean un formato de ciudad: la histórica-clásica, parte de valores, costumbres e hitos, lo que el habitante vive en un entorno cuyos 


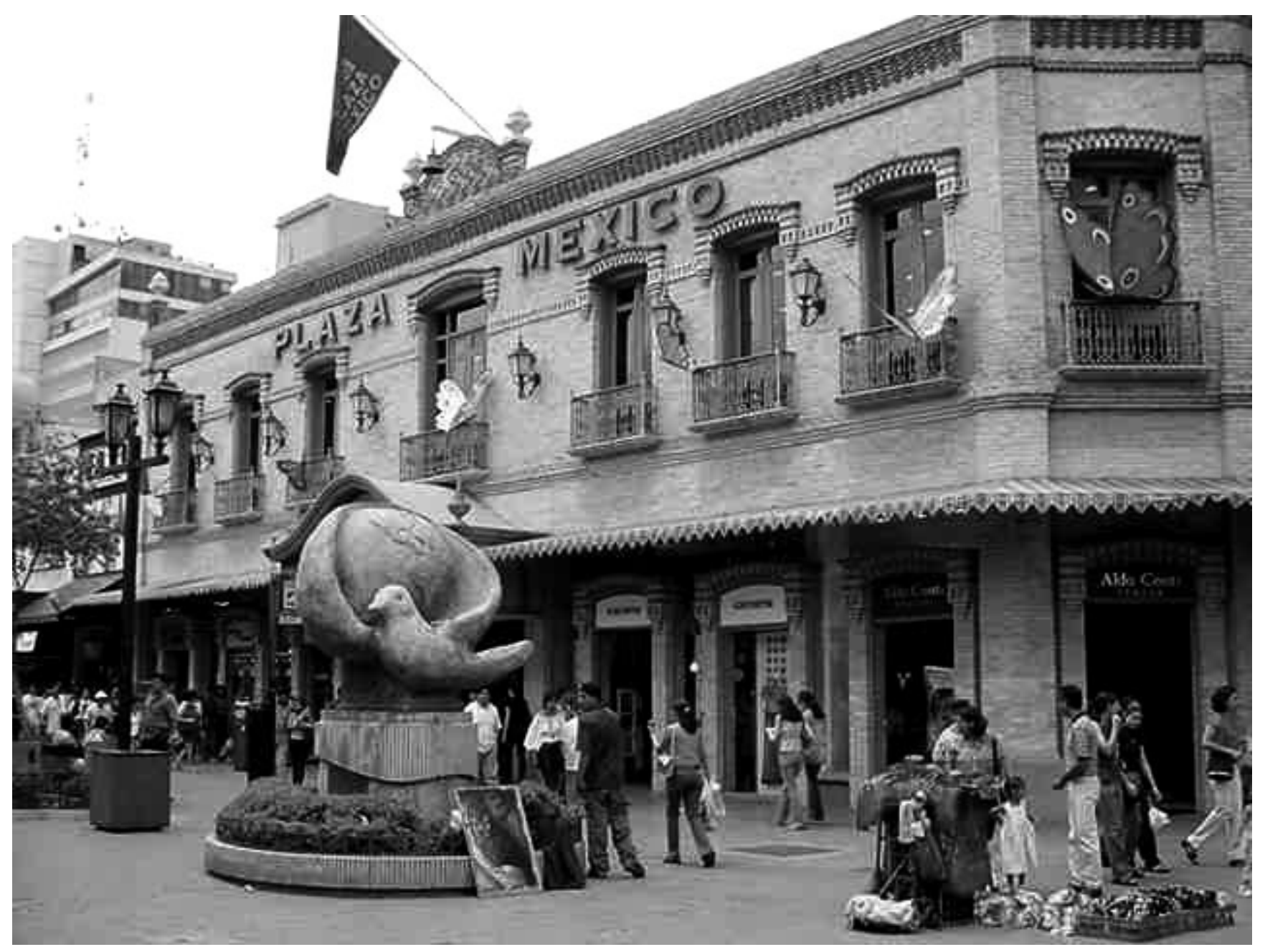

Andador Morelos, Monterrey, NL. Foto: Arturo Villa.

objetos arquitectónicos y urbanos se basan en antecedentes percibidos en guerras, conquistas y herencias atribuyéndole la faceta sociocultural que arraiga un estilo arquicultural. El caminador de estas ciudades supone un alto grado de conocimiento por vivir, sentir, convivir, estructurar la ciudad.

La otra cara de la moneda es la potencialización de la industria y comercio a gran escala proyectada por la modernidad; el alto desarrollo técnico-tecnológico creciente. En esta dinámica, el caminante vive a un nivel superior al desplazarse. El día y la noche se vuelven más cortos y, por tanto, los meses y años, consecutivamente, son parte de un alto estrés físico para el cuerpo humano, llevándolo a degenerarse más rápido. El tejido urbano es una constante para enfocar desarrollos habitacionales a gran escala, vías de comunicación, centros de recreación, de servicio, plantaciones de centros de mando gubernamental-empresarial y parques industriales, y los espacios públicos son moderados por la calle en escalas de alto impacto para la vida urbana.
El cambio de masa demográfica, variable en aumento, es donde las ciudades son un amortiguador que resiste los embates del habitante que día a día se sujeta a factores tecnológicos, siendo el hombre nómada y sufriendo el fenómeno de sedentarismo para permanecer en grupo, emprender actividades, organizarse y descubrir una estratosfera de poder y núcleos que desencadenarían grandes sistemas económicos y políticos concretándolo a conflictos de poder de querer más, de no conformarse con lo que se tiene. La resultante es un mundo no organizado, que sufre los embates de un sistema de gobierno urbano de poder global donde cada habitante ordinario es un elemento de consecuencias.

\section{Transporte y espacio público}

La historia de la urbanización y la sociedad ${ }^{2}$ se enfoca en que las ciudades crecen a un ritmo inhóspito. El transporte urbano es la amalgama para que el 


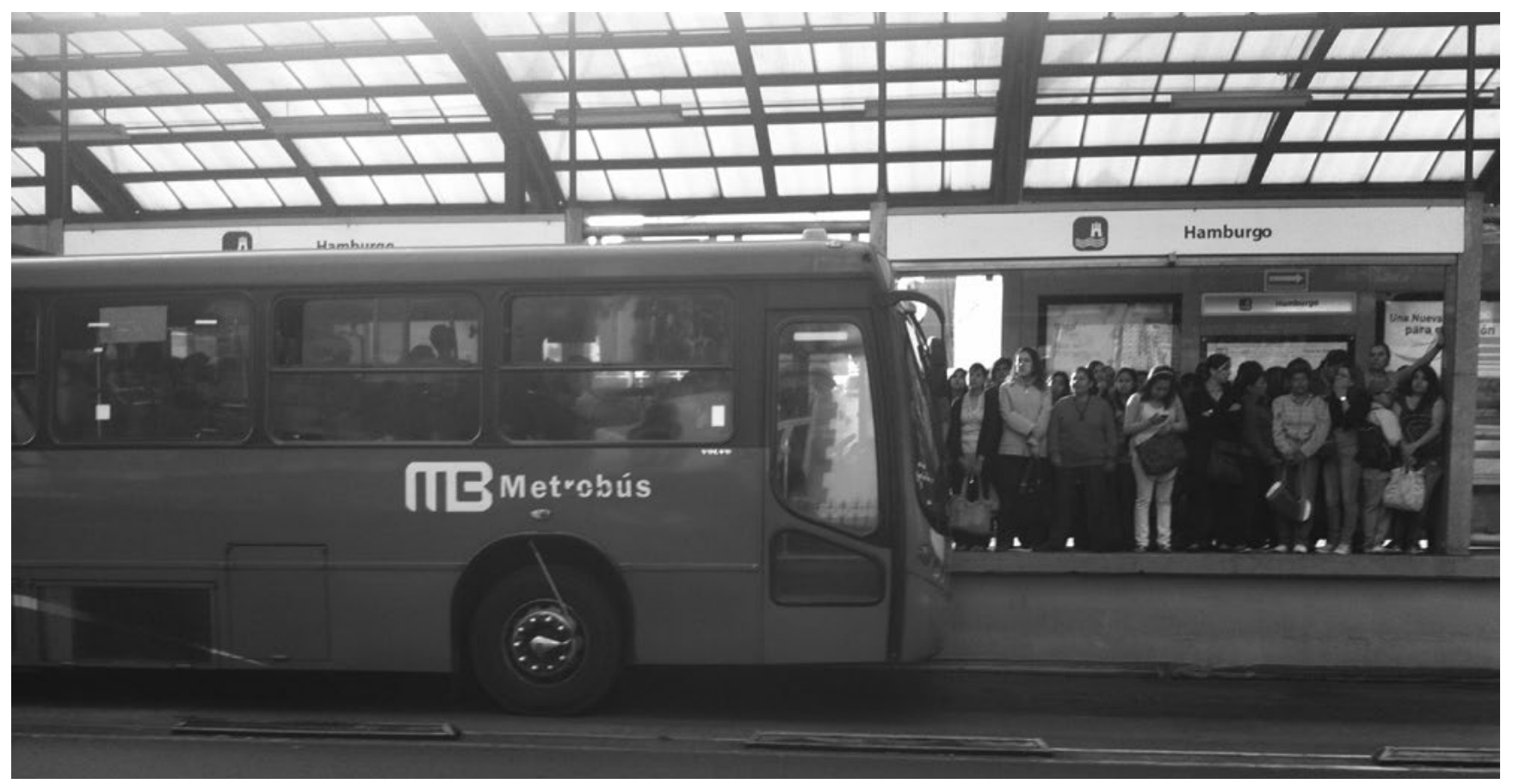

Estación Metro Hamburgo, Ciudad de México, DF. Foto: Arturo Villa.

ciudadano explore el territorio y posibilite el crecimiento de las ciudades ${ }^{3}$ en superficie, acumulando espacios arquitectónicos insospechados y sin grandes trastornos de tiempo. Si se parte de que los tranvías vinieron a amortiguar el desequilibrio vial y el consecuente caos, posteriormente el metro sería una amalgama que recorrería las entrañas de la tierra y el auto, inicialmente, un producto de lujo y primera necesidad para los años venideros.

Conforme pasa el tiempo, el transporte es una puesta en segundo plano para el hogar al desprender múltiples usos como guardarropa, mesa de trabajo, dormitorio, espejo, un espacio privado e interactivo a lo público que cumple espasmos sociofugos y sociopetos. Primero acciona lapsos cortos de tiempo de estancia y permanencia y después dispone estancias más duraderas en uso y actividad. El transporte urbano es un naipe para el ciudadano que recorre terreno a explorar y posibilita el crecimiento de sistemas de vialidad hasta los límites más insospechados, con trastornos y afectaciones al acrecentar trazos de vías de comunicación en sentido continuo y discontinuo para proyectar modelos de calles.

Sentido de la calle

Las calles se asfaltan para moderar desplazamientos de habitantes y vehículos; delimitadas por guarniciones amarillas que salvaguardan una cintilla peatonal de concreto o piedra volcánica que es bautizada como banqueta; lo anterior hace aludir a las palabras del personaje de Marcovaldo. "Ciudadano preocupado por la ciudad. Entristecido por el espacio público. La carencia de árboles y espacios verdes para respirar. La calle se coloreaba cada día de asfalto para caracterizar y decorar todo el contexto. Todo camino a recorrer sería grisáceo." Palabras de un personaje que aterriza las ideas a la actualidad para crear sistemas de vialidad al colocar señales de tráfico como el semáforo que decora y controla el flujo de vehículos.

Las ciudades tradicionales no están preparadas para este tráfico y presentan un número infinito de congestionamientos. Sobrevivir a una conglomeración de vehículos, trasladarse de sector a sector, llegar al corazón de la ciudad, es para realizar alguna actividad; llevar a los hijos a la escuela para estar a tiempo en el trabajo y visitar por la tarde algún museo o parque particulariza el juego de actividades ordinarias. El desenvolvimiento y comportamiento del residente ${ }^{5}$ que se descifra al trasladarse de sector a sector interpreta la totalidad de la urbe, abundante en la afluencia de masas heterogéneas urbanas que saturan los lugares públicos.

¿Cómo entender el espacio público moderado por la calle en la vida del residente en las ciudades? El espacio público urbano conceptualiza la factura construida por el hombre, proyectada por toda 


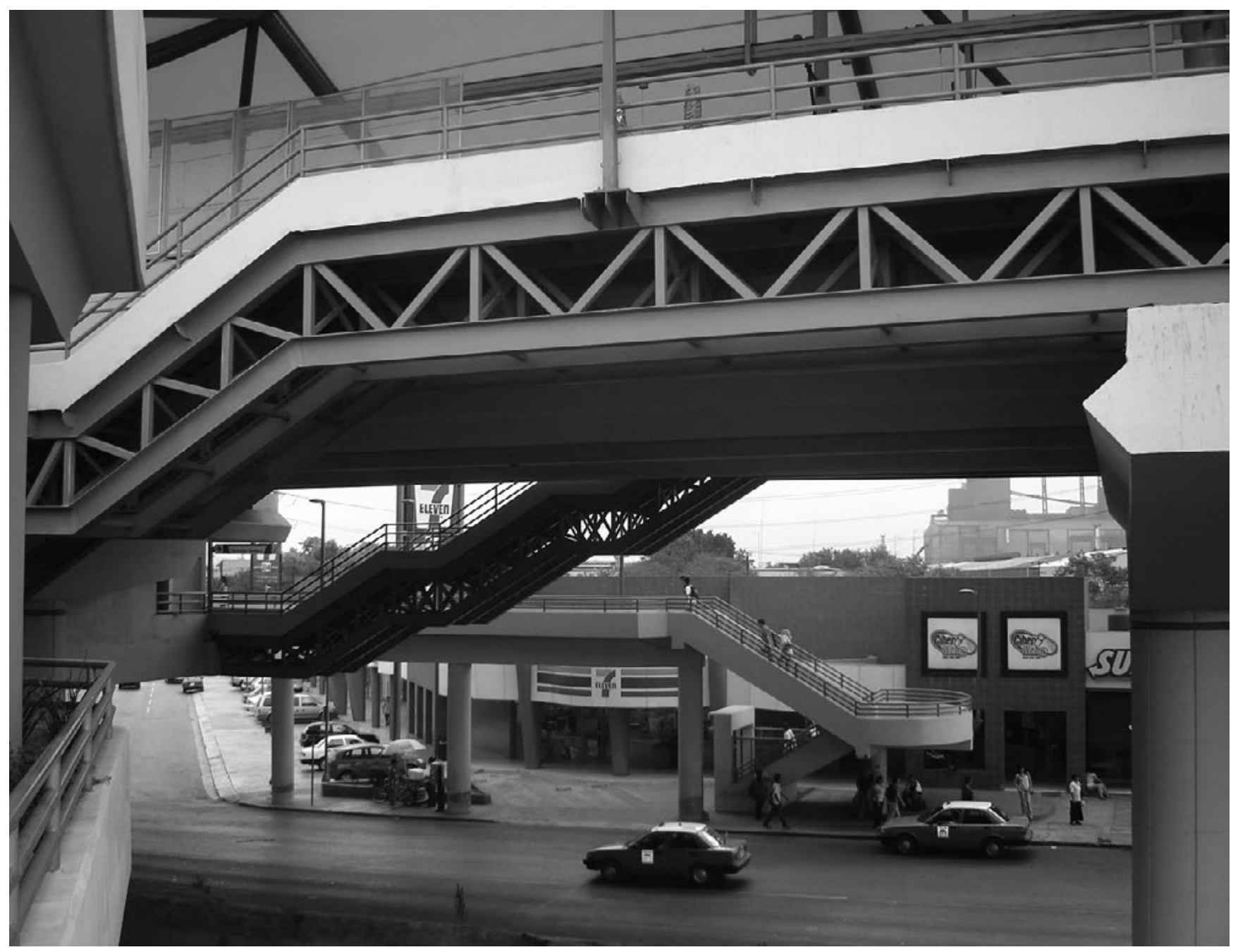

Avenida Universidad. Estación Metro UANL, San Nicolás, NL. Foto: Arturo Villa.

construcción de edificios, centros habitacionales y de trabajo. Espacio público donde cada habitante dimensiona la justificación a la rutina multicultural y es obligado a mantener un comportamiento estándar para cada trayecto-distancia, en cada espacio u objeto arquitectónico.

Ningún lugar público es transferible, no acciona ejercicios catastrales y escritura notarial. No es un documento que ejerza el poder de adquirirlo. Es de todos. Cada punto público es libre y descarta la no producción de edificaciones formales pero síla atracción de formadores de espacios indocumentados, lo que lleva al ejercicio de un notario público que determine la legalidad de la superficie que no puede ser construida sobre lo construido. Lo público descifra los senderos del bosque y la selva, que fueron construidos espontáneamente con muros verdes y raíces para el paso de los extraños y los animales salvajes.

La actualidad de las ciudades demuestra su situación en fenómeno metamórfico debido a la red de sistemas de comunicación urbanos como son las calles. Son ramales que se entretejen para estructurar modelos urbanos que derivan en la elaboración de un sistema vial de comunicación sectorial e interactiva al movimiento. La calle es moderada por la proyección del espacio público. A más espacio público, más calle.

La planeación urbana y social motiva e incita la construcción. Cada escenario por construir es merecedor al desfogue en rutas, trayectos y lugares de esparcimiento que, en conjunto, esclarecen el tipo de comportamiento que desencadena a la acción en la ciudad; actividad reflejada al caminar, tocar, respirar, jugar, desplazar, convivir, interactuar, sufrir. Ahí se activan los flujos que son subrayados en toda calle.

Si se conceptualizan los trazos de calles pueden distinguirse en reticular, lineal, curvilínea, diagonal y súper-manzanas y en planos verticales u horizontales. Conceptualizar a Esmeraldina ${ }^{6}$ hace proyectar un gran sistema reticular, formador de calles, canales en sentidos de zigzag, subidas y bajadas, de planos 


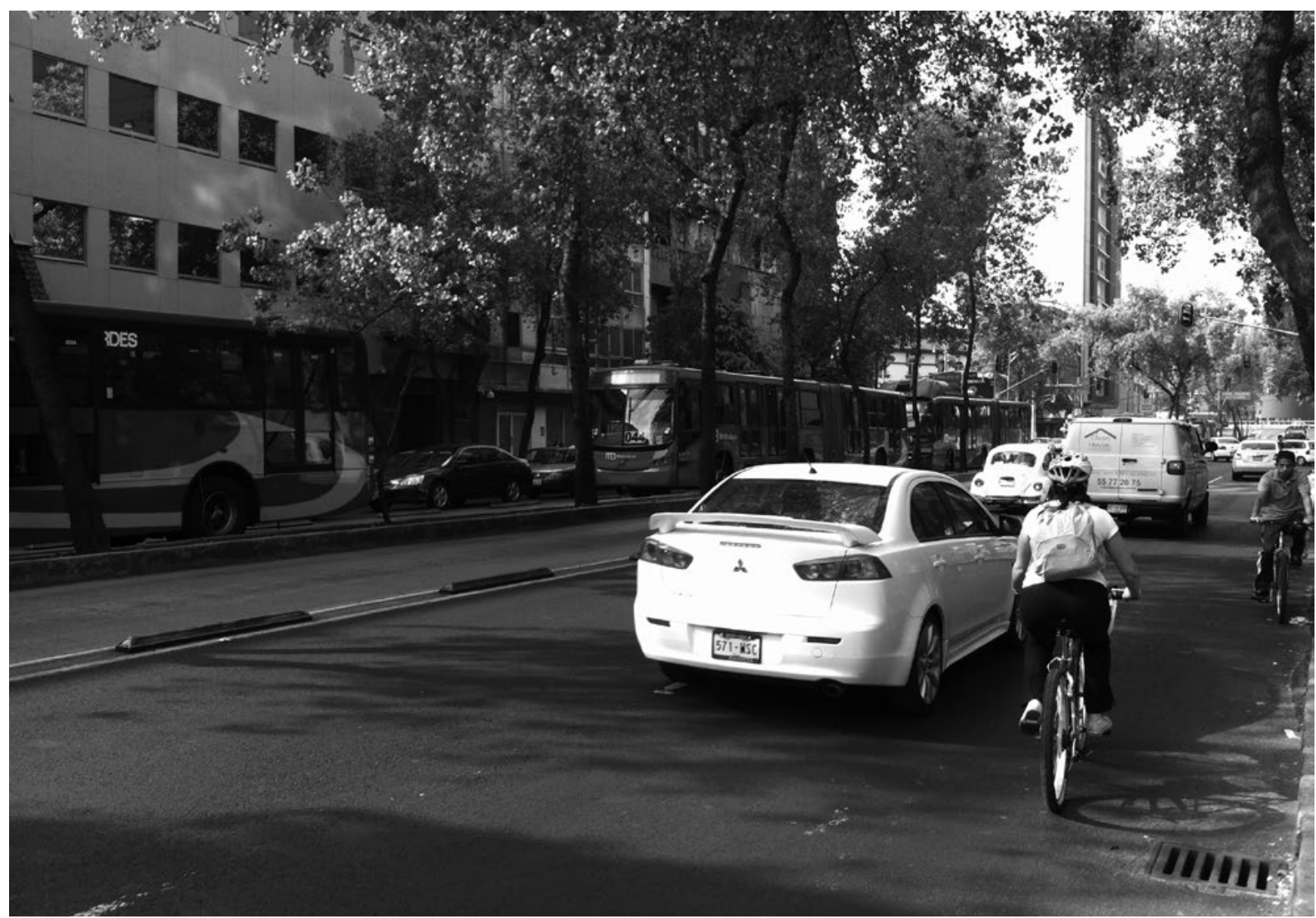

Estación Metro Hamburgo, Ciudad de México. Foto: Arturo Villa.

continuos y activadora en la vida local. Los espacios públicos ejercen operaciones que restan y suman flujos de posiciones, manifestaciones, encuentros, pretextos, disputas, elogios para alzar la voz, hasta encontrar la muerte. Se han presentado en el pasado conflictos bélicos que han dejado huella, desnudando la ciudad hacia una vida marchita, con cicatrices en sus recorridos.

Los recuerdos de las ciudades bélicas siguen latiendo a través de fenómenos psicosociales y culturales en cada sistema urbano a nivel global; actuando contemporáneamente en la movilización de grandes masas de habitantes que alzan la voz para ser escuchados ante el heterogéneo modelo global de gobierno urbano, sediento de poder económico y natural. Aquí el concepto habitar vive la lucha en desigualdad, se desmoraliza y enferma su alma.

\section{LUCHA EN DESIGUALDAD}

Pudiera ser también el resultado de una posición geográfica y del clima lo que designa un tipo de habitante que se desenvuelve a diario en la falta de oportunidades potenciales.? Las étnias urbanas que caminan y trabajan en las banquetas personifican fantasmas a la integración de ciudad. La posición geográfica y el clima puntualizan el comportamiento de este habitante y sus etnias culturales para involucrarse en los tejidos de asfalto y concreto.

México desprende 62 pueblos indígenas y cada uno tiene su propia cultura que camina con un traje mestizo desgastado. ¿Qué sentido tiene reconocer a estas culturas distintas que reclaman sus derechos sin perder su propia identidad e integrarse a una sociedad urbana injusta que camina y vive haciendo calles? Se desgastan ante la falta de articulación y voluntad de apreciar el valor agregado cultural; ambulan como fantasmas en cada acera tratando de comercializar algún producto fabricado con sus manos y materia prima netamente original.

Dichas etnias ven a una civilización que poco a poco ha sido brincada por otra civilización formal apoderada del consumismo desmedido e industrialización a gran escala. Se ven en escenarios superpuestos como vitrina para contener sus objetos a 


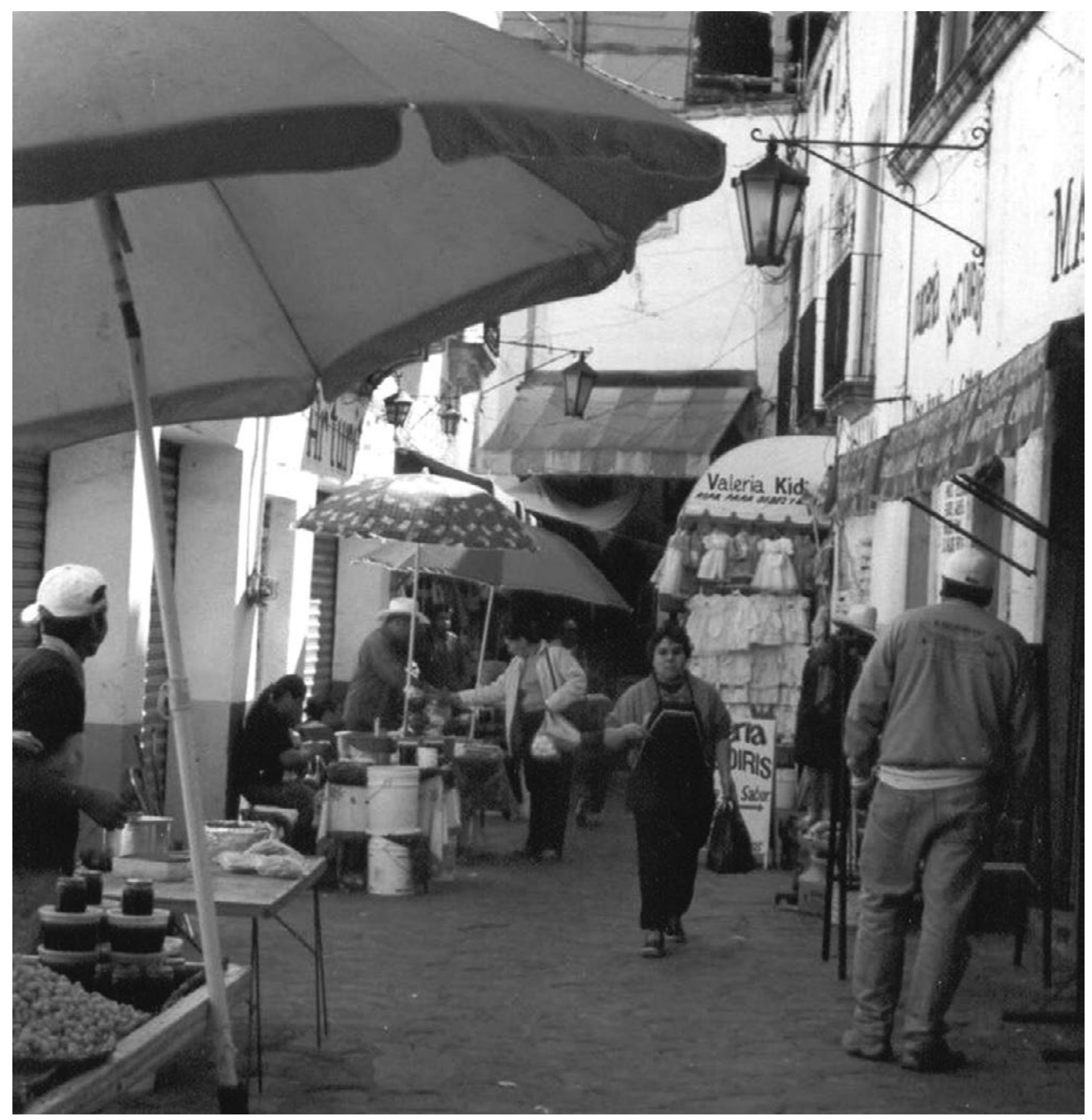

Callejón del tráfico, centro de Zacatecas, Zac. Foto: Arturo Villa.

la venta al público. La vida en las calles tonifica un sinfín de acotamientos 8 para entenderla, porque no es un pretexto impuesto por los urbanizadores empresariales.

$\mathrm{Al}$ caminar entre calles de las ciudades mexicanas, el crucero impacta en afluencia de caminantes, edificaciones, señalamientos, aforo de vehículos y transporte urbano diverso. Es característico visualizar pequeños espacios comerciales informales, indocumentados ante un sistema administrador de impuestos, sin leyes urbanas, distinguidos por formas geométricas y construidas de estructuras metálicas cubiertas de lámina. Sus muros fabricados por un perfil de acero o tubo cuadrado darán función de bastidor para superponer un seriado en láminas, más la suma de estampados de algún cartel de lucha libre o futbol. Los puestos de revistas y periódicos imparten el trajín de la caminata y fusionan el paracaidismo callejero sobre el derecho de vía. Son lugares que dispone una tradición histórica. ${ }^{9}$

Esta acción urbana ya se efectuaba en aires medievales con un habitante que leía un pergamino avisando un acto en las primeras conformaciones de 


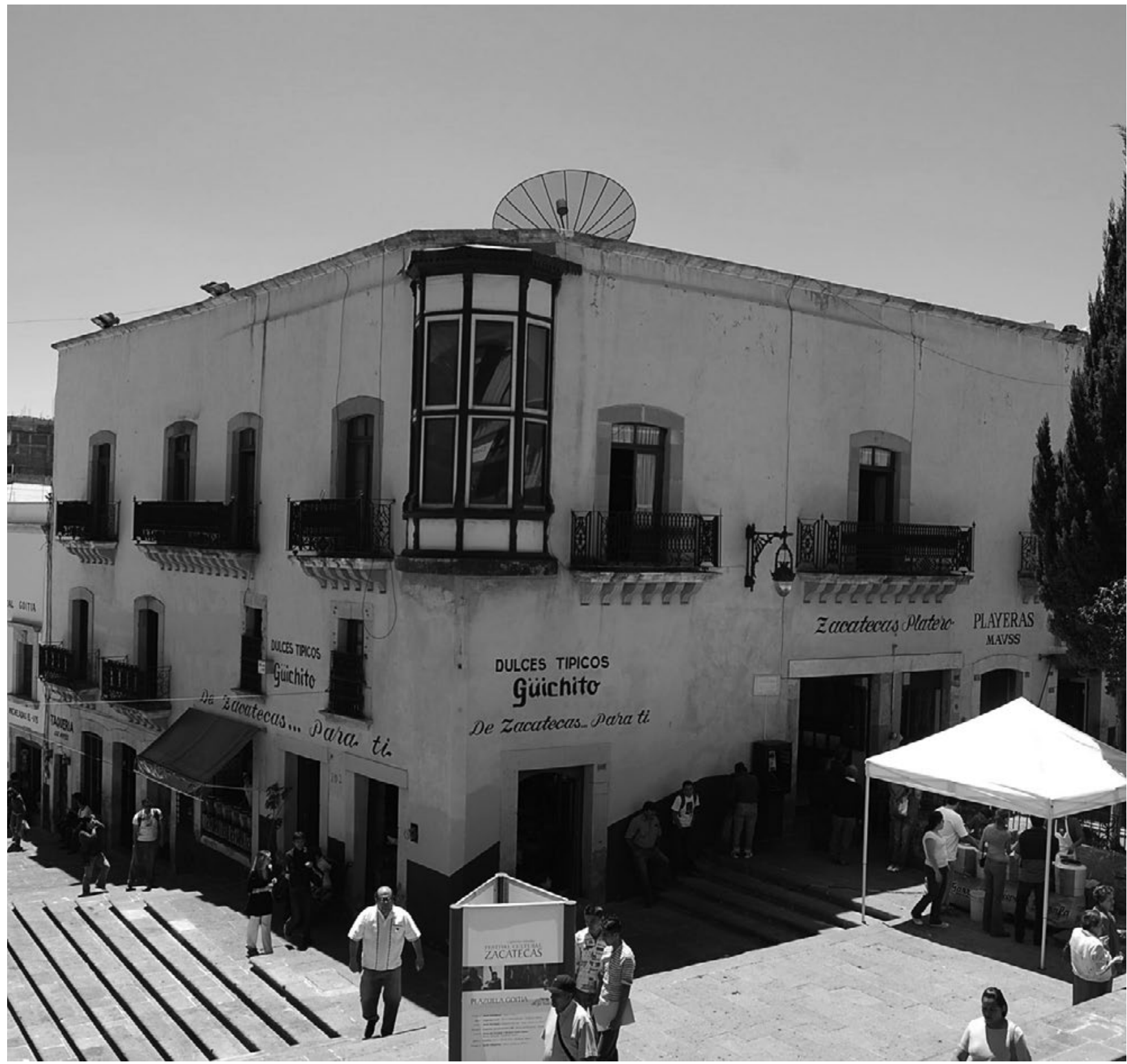

Plaza Goitia, centro de Zacatecas, Zac. Foto: Arturo Villa.

comunicación urbana. En la cultura mexicana, en la época de oro del cine nacional, se mostraba aquel habitante que vivía en las vecindades y salía por la madrugada a cierta esquina a esperar a que llegara el bloque de periódico. Reuniéndose todo vecindario sobre el puesto de venta de comida o cenaduría vecinal donde existía la doñita que era la madre de todos los niños o jóvenes que se dedicaban a la venta del periódico, "mamá panchita" era su pseudonombre de cariño y conocida por todo los del sector que se dedicaban a la venta de la nota periodística.

El actor Mario Moreno Cantinflas personificó a aquel caminante de raíces populares y la venta de periódicos ubicados sobre algún crucero, gritando la nota. Qué decir de aquel actor que personificó al pachuco, German Valdez Tin Tan, o Antonio Espino Clavillazo, entre otros, que personificaron en carne propia la vida del caminante que vivía en la puesta de los escenarios públicos postulando los servicios de venta de periódico y perceptivamente determinaban el rostro y su grado de cicatrización urbana ante un cruda enfermedad producida por la desigualdad y la inestabilidad económica.

Los puestos de comercio de esta envergadura están al servicio de la interacción y protección. La expansión de estos espacios fuera de las reglas urbanas involucra a la permanencia de tiempo por parte de los locatarios. Son casa-habitación-popular rodantes 
donde postulan necesidades de protección y comercialización. El transeúnte es atraído por la voz de la marchanta que desprende un cordial saludo. Estos comerciantes muestran dote especial de publicidad de algún producto al exclamar. Ahí viven, junto al radio y la tele para ver alguna telenovela que los involucre en el entretenimiento anticultural. Comen ahí, colocando una parrilla o microondas con diablito improvisado.

Son un grupo de familias que han pasado el puesto de generación en generación que, ante el crecimiento familiar, también algunos hijos adquieren su propio establecimiento en otros lares. El teléfono celular es indispensable porque se comunican diariamente para inventariar sus productos y socializar experiencias. La vida de estos habitantes es concentrarse la mayor parte de los días en su establecimiento. Es una rutina mecánica. Levantarse diariamente a las cuatro de la mañana para organizar e ir por el "papel gris" y llevarlo al puesto. Todo esto es una cadena de rutinas ${ }^{10}$ para hacer un cordón proyectual, porque si no hay venta no hay para pagar y vivir (este último clasificado en la renta de cuartos donde habitan, cilindro de gas, luz, agua, escuela de hijos, saldo de teléfono celular y comida).

En países desarrollados, por el contrario, no se demandan estos establecimientos irregulares en las calles a la luz de las leyes urbanas. Los centros comerciales amortiguan la demanda a partir de formalidades; vistas de un local de ciertas medidas en cadena de franquicia para justificar el diseño del espacio y la logística de mercadotecnia. La tecnología en estos países contribuye a la forma de ubicar y diseñar este mobiliario urbano. Por lo general, el restaurant o cafetería, se tiene a manera de contenedor; se oferta refresco, frituras o café instantáneo, solamente es necesario colocar algunas monedas y obtendrá lo seleccionado. La estructura urbana de dichos países parte de ciertas capas evolutivas para saber en qué época se está viviendo como reflejo de coyunturas sociales y culturales." En sus calles, el uso de la tecnología de punta automatiza toda acción para el habitante urbano.

En México se formalizan los espacios públicos y el mobiliario urbano para la comercialización pública. Las planchas de concreto como circulaciones en " $\mathrm{U}$ " en su paso de vialidad, albergan marchantes con una variedad de productos para comercializar a la espera del semáforo que indica el siga. Se acercan con una caja de chicles, artesanía, bolsas, muñecas, cacerolas de barro, tarjetas de crédito celular, productos del sistema activo indígena y territorial de grupos urbanos.
Se habla de grupo étnico todavía en estos tiempos. No cuesta trabajo integrarlos, no valorizarlos y sustituirlos por la manufactura de la industrialización y tecnología del siglo xxı. El mestizaje de la cultura española e indígena trascendió en cada cultura prehispánica para connotar una evolución utópica. Actualmente, México tiene más de I5̆ millones de indígenas y a pesar de poseer alrededor de la quinta parte del territorio nacional, viven explotados en su propios hábitat y recursos naturales. Ellos decidieron ser mexicanos y preservarse con sus propias identidades y culturas.

Pero son mexicanos separados de las ciudades como el agua y el aceite. Indígenas que viven en casi todo el territorio mexicano, pero invisibles. Autistas a los ojos del habitante urbano. Manipulados, explotados y apartados del sistema, porque ellos siempre levantan la mano. Pocos hablan. Poco expresan: "me da un peso", "me da pa' un taco". Suena el acordeón que toca el indígena mayor, las guitarras que tocan dos menores de diez años, acompañándolos una niña indígena con poca habla y con la postura de sus ojos desconectados de una infancia digna. Ella pide una moneda mientras levanta un vaso de plástico desechable. Son indígenas que visten prendas autóctonas; cantantes de calle para encontrar la moneda en alguna esquina concurrida poco a poco adoptan una práctica singular del oído musical, ampliando una cartera abundante del género popular. Más tarde se reunirán en otra esquina con el fin de juntar ciertas cantidades de dinero para entregarlas al padrino. A estos caminadores les quedará el sudor y la voz seca porque tienen que entregar las monedas. Los niños serán acreedores de una comida-cena, para dormir en un pequeño catre y sábana como cobija. Continuando así los días y meses de cada año.

La calle podadora de encuentros públicos ${ }^{12}$ observa a familias que dicen serlo, pero son grupos desapartados y rechazados de sus padres natos. Conservan su trabajo debido a que subsisten en las redes públicas; son grupos de habitantes que construyen territorios públicos para trabajar y manipular personas con discapacidad física. Como objetos, son ubicados en vías de comunicación y transición vial. Y los reubican, no permanecen en el mismo sitio de operación.

Piden una moneda por poseer una discapacidad física, limpiar el parabrisas; el tragafuegos colorea su rostro de blanco y antepone una lágrima de color negro simbolizando la falta de integridad social. Actores que personifican el tipo de riña circense y 
artística, caracterizan la lucha de esquinas. Jóvenes cuya edad no les adjudica la ciudadanía, personifican a diario la cartelera de alguna lucha libre de cuadrilátero mexicano. La diferencia es la nula existencia de límites. Todalamarimbapeatonal la someten como delimitación de espacio para su acto. Tienen la esperanza de reunir monedas y billetes que se adhiere a su bolso del pantalón desgastado por la oferta de trabajo, entregando a diario una suma al jefe. Ellos tendrán derecho a tocar el dinero pero no gastarlo. La sed y hambre pasará a segundo término. Aquí los actos están cuantificados por días, generando entregas económicas. Si no obtienen el número estimado serán desechados.

Es interesante la determinación territorial y jerárquica en el uso mismo del espacio público, esclarecido por el franelero, un habitante que trabaja día a día, dando vida al gremio sindical de franeleros. Losfranelerosseadhierenacadacalleoestacionamiento de algún supermercado, utilizando uniforme como requisito laboral para distinguirse de otro gremio que puede invadir las zonas de trabajo; su trabajo consiste limpiar, cuidar y mantener intacto el vehículo. La exclamación de su voz es la herramienta más poderosa para la labor de convencimiento, anunciando el pase de salida de vehículo a vehículo. Sus palabras son intervalos parafraseados en "ahí viene el perrón", "sale, sale", "ahi viene el bonito", son modismos para la obtención del salario justificado: la moneda.

\section{VOCES DE LA CIUDAD}

La vida en el sistema urbano puede parecer tediosa, como si no avanzara el tiempo. Son escenarios contaminados, abundantes de publicidad para perfilar un tipo de vida optativa y heredarla a otras generaciones. Actores que nacen y se desarrollan en el escenario público, prevaleciendo el rostro de un habitante que busca a como dé lugar insertarse e involucrarse en la vida pública sin el rechazo de la sociedad consumista. Las calles son la voz de todos los que vivimos en las ciudades; generadoras de encuentros culturales; detonadora de corrientes y tribus urbanas. ${ }^{13}$ Son la noticia que se aprecia en el televisor; contenedores de imágenes; largas manifestaciones que alzan la voz para ser escuchados, proyectándose en una planeación de corto, mediano y largo plazo para vivir en esta ciudad.

\section{$-\operatorname{notas} \cdot-$}

\footnotetext{
' Paul Singer (1973), Economía política de la urbanización, México, Siglo XXI Editores, pp. 56-7o.

2Vicente Verdú (2004), La ciudad inquieta, El urbanismo contemporáneo entre la realidad y el deseo, Madrid, Fundación Santander Central Hispano, p. 556.

${ }^{3}$ Jan Bazant (2004), Asentamientos irregulares: Guía de soluciones urbanas, México, Editorial Trillas, p. I02.

${ }^{4}$ Ítalo Calvino (2010), Marcovaldo, Madrid, Siruela.

${ }^{5}$ Paul Singer (1975), op. cit., p. 80.

${ }^{6}$ Ítalo Calvino (2014), op. cit.

7 Jan Braudilard (1974), Crítica de la economía política del signo, México, Siglo XXI Editores, p. I22.
}

${ }^{8}$ Vicente Verdú (2004), op. cit., p. I5̌6.

9 Harry Shapiro (1975), Hombre, cultura y sociedad, México, Fondo de Cultura Económica, p. 23I.

1o Armando Flores (2002), Ornamentaria. Lectura cultural de la arquitectura regiomontana, Monterrey, Universidad Autónoma de Nuevo León, pp. 9o-ıı.

"Geoferry Baker (1998), Análisis de la forma. Urbanismo y arquitectura, México, Editorial Gustavo Gili, p. 38.

12. Patricia Richard (2004), Violencia, individuo y espacio vital, México, Universidad Autónoma de la Ciudad de México, pp. 34-45.

13 Juan Carlos Pergolis (2005), Ciudad express: Arquitectura, literatura, ciudad, Buenos Aires, Nobuko, p. I8. 